\title{
MUJERES MAYORES ASTURIANAS: VISIÓN CRÍTICA SOBRE LA MEDIACIÓN TELEVISIVA E INFANCIA
}

\section{THE ELDERY WOMEN OF ASTURIAS: CRITICAL VIEW ON TELEVISION MEDIATION AND CHILDHOOD}

\author{
Dra. M $M^{\mathrm{a}}$ Esther del Moral Pérez \\ emoral@uniovi.es \\ Dra. Lourdes Villalustre Martínez \\ villalustrelourdes@uniovi.es
Universidad de Oviedo. Facultad de Formación del Profesorado y Educación. Departamento de CC de la Educación. Cl Aniceto Sela, s/n 33005 Oviedo (España).

Se recogen las opiniones de las responsables de las Asociaciones de Amas de Casa asturianas, preocupadas por el cumplimiento de la Ley General de Contenidos Audiovisuales LGCA de las televisiones sobre protección de menores. Denuncian que no se respetan los horarios protegidos, piden la retirada de publicidad engañosa y modelos cuestionables en series juveniles y dibujos animados, critican la manipulación informativa. Demandan rigor para señalar las edades recomendadas de sus programaciones; compromiso para preservar la intimidad de los menores; y responsabilidad para favorecer su desarrollo físico y mental. Además, hacen propuestas para fomentar el entretenimiento y la difusión de la cultura en los espacios televisivos infantiles.

Palabras clave:Protección de menores; conciencia crítica; mediación televisiva; audiencias mayores.

This study gathers the views of the people responsible for the Asturian Housewives Association, who are concerned about child protection and the compliance of the LGCA (General Law for Audiovisual content in Spanish) by the television industry. They argue that child protection schedules are not respected. They ask for the withdrawal of misleading advertisement, and questionable models shown in teen series and cartoons, and they, criticize the manipulation of information. The leaders of the association demand first, that the issue of indicating the recommended age of programming is addressed with all due rigor; second, the commitment to preserving the privacy of minors; and third, responsibility to promote their physical and mental development. Also, they make proposals to encourage the dissemination of entertainment and cultural in children's television programs.

Keywords:Child protection; critical awareness; television mediation; senior audiences.

Píxel-Bit. Revista de Medios y Educación. No 46. Enero 2015. ISSN: 1133-8482. e-ISSN: 2171-7966. doi: http://dx.doi.org/10.12795/pixelbit.2015.i46.11 


\section{Introducción.}

Desde hace décadas, en el ámbito internacional, la UNESCO NORDICOM (1999) lleva promoviendo estudios y conferencias internacionales centrados en el impacto de los medios y los menores, algunas de sus publicaciones contribuyen a la formulación de una serie de recomendaciones, destinadas a los estados miembros, sobre educación para los medios, así como propuestas para la creación de espacios específicos para la infancia en los medios de comunicación, defendiendo la educación mediática como parte esencial de los derechos del ciudadano, y recomendando su introducción en los currículum de educación formal, informal y permanente.En el plano legislativo, si bien es cierto que ya existían normativas en la Unión Europea y en España como el Código de Autorregulación (VVAA, 2004) suscrito por diferentes operadoras nacionales para fijar franjas horarias de protección de los menores, sin embargo, no había un marco legal que explicitara y sancionara su incumplimiento, hasta 2010, con la Ley General de Contenidos Audiovisuales (LGCA) en España, se intenta garantizar los derechos a los consumidores $\mathrm{y}$, proteger a los menores frente a los contenidos audiovisuales, regulando aspectos formales, prohibiendo la emisión de contenidos violentos o pornográficos en horarios protegidos, etc. Actualmente, el horario de protección del menor se fija de 6:00 a 22:00 horas, y el superprotegido, de 8:00 a 9:00 y de 17:00 a 20:00 horas, lógicamente al tratarse de franjas horarias cuya audiencia potencial son niños obligan a cuidar la selección de contenidos. La Ley 7/2010 matiza que: «las autoridades audiovisuales deben velar por el cumplimiento de los códigos y, entre éstos, del Código de Autorregulación de Contenidos Televisivos e Infancia». Donde se destacan las obligaciones de las cadenas para reforzar la franja de horario protegido con objeto de procurar una adecuada alfabetización de los niños: evitar el lenguaje indecente o insultante, incluyendo los sms que aparecen en pantalla; eliminar mensajes o escenas de contenido violento o sexual carentes de valor educativo o informativo en los programas dirigidos al público infantil o en sus cortes publicitarios; etc.

A pesar de ello, tras varios años de vigencia de la LGCA, la Asociación de Consumidores Audiovisuales (ACU), apoyada por el Ministerio de Salud y Políticas Sociales (Perales, 2011), y posteriormente la Asociación de Consumidores de Medios Audiovisuales de Cataluña (TAC, 2013) y la Federación de Asociaciones de Consumidores y Usuarios de los Medios (iCmedia, 2014) elaboraron varios informes constatando un alto grado de incumplimiento por parte de algunas cadenas televisivas en materia de protección de menores. Si bien es cierto que el grado de penetración de las Tecnologías de la Información y Comunicación en la sociedad y en los hogares es cada vez más elevado, y que la regulación basada en los horarios protegidos contemplados en la LGCA no es extensible a los contenidos audiovisuales dirigidos a la infancia que se emiten a través de Internet, sin embargo en un intento de acotar el estudio, nos remitiremos únicamente a aquellos que sí lo son, siendo conscientes de la necesidad de establecer políticas globales para una mejor protección y promoción de la infancia. Coincidimos con Buckingham (2003) en que la educación para los medios debe orientarse a dotar a las personas de las habilidades y capacidades 
necesarias para adoptar una actitud crítica y responsable frente a todos los medios (televisión, radio, prensa e Internet). Existen numerosos estudios centrados en la audiencia infantil (Taveras et al., 2006; Iguarta, 2008; Kirkorian, Pempek, Murphy, Schmidt \& Anderson, 2009) que han dejado patente la influencia de los contenidos televisivos en el desarrollo cognitivo y social de los menores. Los niños acceden despreocupados a la pequeña pantalla, presenciando modelos de comportamiento y valores que no siempre son los más apropiados como referentes en su vida cotidiana, dado que su análisis crítico es muy limitado según se extrae de las investigaciones de Gabelas y Lazo (2008) y de la de Guerra y Renés (2010).Además, dado que los mecanismos arbitrados, a nivel institucional -como la aprobación de la LGCA (2010)-, no han surtido los efectos esperados, hoy los esfuerzos deben dirigirse a desarrollar iniciativas de alfabetización mediática tanto en la escuela (Pavón, 2005) como en instituciones no formales como señala Luis Boza (2005), o en el seno familiar desde diferentes perspectivas, tal como proponen Pereira, Pinto y Pereira (2012), y ésta última fue la razón que impulsó la presente investigación.

\section{Responsabilidades frente a la mediación televisiva de la infancia.}

Al tratar de identificar a aquellas personas encargadas de cuidar de los menores en el contexto familiar y de velar por su educación, se constató que, de un tiempo a esta parte, son las figuras de los abuelos y las abuelas las que están adquirido un gran protagonismo. El estudio del Ministerio de Sanidad, Política Social e Igualdad (2010) señala que la mitad de los mayores dedican un promedio de seis horas diarias a sus nietos. Los denominados «superabuelos» los cuidan de día y de noche, los acompañan al colegio y los recogen, les alimentan, juegan en el parque y ven la televisión con ellos, etc. No cabe duda que constituyen piezas clave que posibilitan el equilibrio en las familias compensando las ausencias de sus progenitores por motivos laborales o personales, y convirtiéndose en agentes coeducadores en este nuevo escenario familiar. Sin ánimo de teorizar sobre este fenómeno sociológico emergente como hacen otros autores (Pinazo \& Montoro, 2004; Mestre, Guillen \& Caro, 2012), sin embargo, en relación a la temática que aquí se aborda, se evidencia la brecha entre las tres generaciones que hoy conviven juntas respecto al uso de las tecnologías y medios de comunicación, en especial, de la televisión. Es fácil constatar cómo cuando los nietos regresan a casa tras las clases, dedican buena parte de su tiempo a ver la televisión, unos los canales temáticos infantiles (Clan TVE, Boing, Disney Chanel, etc.) y otros comparten, incluso, el visionado de teleseries y programas dirigidos al público adulto emitidos en horario protegido. Muchos de los mayores se sobresaltan al presenciar conjuntamente con ellos-, escenas con una excesiva carga violenta o sexual; escuchar vocabulario obsceno, insultos y descalificaciones, etc., sintiéndose impotentes para preservar a los menores de esos envites al considerar que carecen de las capacidades básicas para reclamar y hacer cumplir lo que de forma intuitiva- entienden debería estar regulado por ley, como sucede. Así pues, partiendo del convencimiento de que el único modo de que exista una incidencia real de la audiencia en la emisión de los contenidos televisivos, -o en los medios, en general-, pasa 
por que ésta esté dotada de las competencias mediáticas necesarias para desenvolverse en el nuevo panorama audiovisual, desde aquí se apuesta por el diseño de un plan formativo ajustado a las características de este colectivo especial como son las personas mayores abuelas en su mayoría, y cuidadoras de sus nietos/as-, que se oriente a activar su conciencia crítica, es decir, a cualificarlas para que sean capaces tanto de analizar, cuestionar y juzgar críticamente los mensajes que reciben, como para activar su participación y dirigirla a salvaguardar sus derechos y demandar una mayor calidad en los programas que se emiten (Del Moral \& Villalustre, 2013).

Además, no cabe duda de que su implicación en asociaciones capaces de canalizar las demandas de los usuarios de los medios redunda en la calidad de los mismos, lo cual puede servir para impulsar su participación, apelando a su responsabilidad ciudadana en tanto agentes difusores de cultura y canales socializadores (Boza, 2005). $\mathrm{Su}$ vinculación a estas organizaciones civiles puede contribuir a impulsarles a defender sus derechos y, más concretamente, los de los más débiles, menores y jóvenes, mediante campañas informativas sobre la regulación audiovisual, herramientas de control y protección, procedimientos de reclamación y participación en los medios, etc. (Fuente, 2010). Por ello, en el marco de las acciones formativas de la Consejería de Salud y Servicios Sociales del Principado de Asturias, dentro de la Agencia de Sanidad Ambiental y Consumo, se diseñó un programa de «Formación de formadores», cuyas líneas de actuación prioritarias se orientaron a formar la conciencia crítica de los consumidores e impulsar su responsabilidad ciudadana. El cual, en primera instancia, se dirigió a las responsables de las 35 delegaciones locales que integran las Asociaciones de Amas de Casa del Principado de Asturias (AACPA), conscientes tanto del alcance radial que podría suponer su formación, puesto que en conjunto cuentan con un total de 6.940 asociadas repartidas entre las mismas; así como de las demandas derivadas de los nuevos roles asumidos por éstas, en su mayoría abuelas, en tanto cuidadoras de sus nietos (Pérez-Ortiz, 2007). Concretamente, se buscaba incrementar su autonomía frente a los medios, al tiempo de convertirlas en difusoras de iniciativas orientadas a enriquecer las programaciones integradas en los horarios protegidos, que ayuden a los responsables de los medios a poner en valor sus cadenas, atendiendo a las demandas de los consumidores finales. Pues, no se puede olvidar que son los consumidores los que finalmente las revalidan contribuyendo a su permanencia o no, quienes sin duda apuestan por contenidos positivos, como señalan Medrano, Cortés, Aierbe \& Orejudo (2010).

\section{Metodología.}

\subsection{Contexto y objetivos de la investigación.}

Tras analizar los documentos elaborados por diferentes organismos e instituciones (ACU, TAC, etc.) en cuanto al grado de cumplimiento de la LGCA por las diferentes operadoras de ámbito estatal y dadas sus críticas conclusiones, se consideró pertinente conocer la opinión de este colectivo especial de mujeres comprometidas, inquietas socialmente, ligadas a asociaciones de amas de casa y con un perfil reconocido de liderazgo, abuelas y amas de casa que se 
enfrentan al reto de su segunda maternidad, cuidado y atención de sus nietos, cuya influencia en las tomas de decisiones familiares están adquirido un nuevo protagonismo.Así pues, se les preguntó sobre cuestiones relativas a la normativa y regulación de los contenidos televisivos en materia de protección a la infancia vigentes, de lo que pudo deducirse su grado de conciencia crítica, responsabilidad social para velar por el cumplimiento de la ley en materia de protección de menores, e iniciativa para proponer pautas para el diseño de programaciones infantiles de calidad. De este modo, la consulta realizada a las responsables de las agrupaciones locales de las Asociaciones de Amas de Casa del Principado de Asturias (APACPA), tenía por objeto constatar: 1) sus conocimientos sobre las franjas horarias protegidas que contempla la LGCA; 2) sus opiniones y grado de acuerdo con la necesidad de regular determinados aspectos para proteger a los menores y, 3) su percepción sobre el cumplimiento de la ley que hacen las cadenas de televisión más representativas del panorama español (TVE, La2, Atresmedia y Grupo Mediaset:Tele5, etc.). Además, de recoger las demandas que formulan a los responsables de las televisiones, así como sus propuestas innovadoras para fomentar el entretenimiento y la difusión de la cultura en los espacios televisivos dirigidos a la audiencia infantil y juvenil.

Tras recabar los datos, se realiza un análisis estadístico de los mismos, empleando un nivel de significatividad del $95 \%$, empleando diferentes pruebas en función de la naturaleza de los datos manejados. Entre ellos destacamos: Prueba de Kruskal-Wallis, mediante esta prueba se realizó una comparación de los rangos promedios de los diferentes gru- pos analizados; Prueba U de Mann-Whitney para contrastar estadísticamente las diferencias entre medias; y prueba de Chi-cuadrado para contrastar si las frecuencias observadas en cada una de las clases de una variable categórica varían de forma significativa de las frecuencias que se esperaría encontrar si la muestra hubiese sido extraída de una población con una determinada distribución de frecuencias.

\subsection{Participantes.}

Las participantes constituyen la población total de las 64 directivas responsables (presidentas y vicepresidentas) de las 35 delegaciones locales que integran las Asociaciones de Amas de Casa del Principado de Asturias (AACPA) -que cuentan con un total de 6.940 asociadas repartidas entre las mismas-, para quienes se diseñó específicamente el curso. Concretamente, el $41 \%$ de las directivas tiene entre los 66-75 años; otro 40\%, edades entre 56-65 años; un 10\% está representado por las mayores de 75 años; y, un 9\% integrado por las que poseen entre los 46-55 años, es decir, el $91 \%$ de ellas tiene más de 56 años. Asimismo, más de la mitad de las mujeres (59\%) posee estudios primarios, un $32 \%$ tiene estudios de formación profesional o bachillerato. Sólo un $6 \%$ de ellas posee título universitario, y un residual $3 \%$ no cuenta con formación alguna. Además, el $42 \%$ manifiesta tener al menos dos hijos, la gran mayoría son abuelas que no desempeñan un trabajo profesional fuera del hogar $y$, en la actualidad, muchas de ellas asumen el cuidado de sus nietos, dedicando gran parte de su tiempo a esta labor. Mujeres con una gran capacidad de liderazgo y dotadas de habilidades para la gestión y organización de sus respectivas asociaciones dado el cargo que osten- 
tan en las mismas (presidentas o vicepresidentas).

\subsection{Instrumentos.}

Por un lado, el cuestionario PROMETE (Protección de Menores en las Televisiones) permitió -a partir de 17 ítems-, describir la población en función de parámetros como la edad, formación académica, número de hijos, etc., y analizar, su conocimiento y grado de acuerdo sobre:

1) Las franjas que abarca el horario de protección de menores de 13 años; 2) La necesidad de regular determinados aspectos contemplados en la LGCA para proteger a los menores; 3) El cumplimiento de la LGCA que hacen las televisiones mencionadas (TVE, La2, Atresmedia y Grupo Mediaset:Tele5, etc.) sobre:a) Aspectos formales: obligatoriedad de informar con anticipación sobre su programación, inclusión de la calificación por edades en sus programas e indicación visual y acústica de los programas para mayores de 13 años; b) Contenidos: respeto a la intimidad y el anonimato de los menores implicados en hechos delictivos o emisiones que discutan su tutela o filiación, prohibición de emisiones de contenidos -en abierto o codificado- que atenten contra los derechos humanos, y prohibición de emitir -en abierto- contenidos pornográficos o de violencia gratuita; c) Aspectos vinculados al consumo yla salud: emplazamiento de productos en la programación infantil, emisiones que potencian el culto al cuerpo o publicidad de bebidas alcohólicas (de más o menos de $20^{\circ}$ ) y tabaco.

Y por otro, las parrillas de registro de las intervenciones de las usuarias tras su participación en los talleres formativos orienta- dos a conocer y analizar los aspectos básicos de la LGCA.

\subsection{Procedimiento.}

La presente Investigación-AcciónParticipativa (IAP) concilia dos metodológicas: a) metodología descriptivocuantitativa, para el análisis y posterior tratamiento estadístico de los datos obtenidos mediante un cuestionario; y, b) metodología cualitativa, apoyada en la participación de las 64 mujeres distribuidas en 5 grupos de discusión, integrados en el taller formativo que duró tres meses orientado a analizar lo contemplado en la LGCA relativo a la salvaguarda de los derechos de los menores, con objeto de recoger sus demandas y preocupaciones más acuciantes en torno a la garantía que ofrecen las cadenas televisivas en esa materia, utilizando una parrilla para el registro de las intervenciones más representativas junto a la elaboración conjunta de un manifiesto final dirigido a los responsables de las cadenas televisivas, con las propuestas que, a su juicio, podrían enriquecer las programaciones desde el respeto a la ley vigente y el fomento de valores pro-sociales que sirvan de referente a los jóvenes ciudadanos.

\section{Resultados.}

\section{A) Su opinión recabada a partir del cues- tionario PROMETE:}

\subsection{Horario de protección de menores.}

El primer ítem iba encaminado a detectar si conocían las franjas del horario protegido en las emisiones televisivas que contempla la actual legislación para la protección de menores. Y, sorprendentemente, se encontró que 
el $82 \%$ de las mujeres sabía que dicho horario abarca de 6:00 a 22:00 horas, y el superprotegido, de 8:00 a 9:00 y de 17:00 a 20:00 horas de lunes a viernes y de las 09:00 a las 12:00 horas los fines de semana. Aunque, considerando que muchas de ellas dedican gran parte de su tiempo al cuidado de sus nietos, parece lógico pensar que controlen lo que se emite en esas franjas en las distintas cadenas de televisión, cuya audiencia potencial supuestamente es infantil.

\subsection{Grado de acuerdo con la necesidad de} regular aspectos contemplados en la LGCA para la protección de menores.

\subsubsection{Sobre la emisión de determinados contenidos.}

Desde el ámbito psicológico se percibe gran consenso sobre la necesidad de preservar a los menores de contenidos que puedan influir negativamente en su desarrollo socioemocional, tales como la violencia gratuita (Imbert, 2002; Bolivar \& Flórez, 2004), la por- nografía (Pérez-Ornia \& Núñez, 2006), el consumo desmedido (Del Río \& Del Río, 2008).

A ese respecto, se quiso saber su opinión sobre los aspectos regulados por la LGCA (Art. 7, Pto. 2) y constatar su grado de acuerdo. Lógicamente, mostraron un alto índice de acuerdo (Tabla 1) en relación a la necesidad de prohibir emisiones de contenidos que atenten contra la dignidad humana, contenidos violentos o sexuales en horarios de protección de menores, así como, publicidad engañosa. Conscientes de que estos programas proporcionan historias y ejemplos de conductas encarnados en personajes, en ocasiones, estereotipados que responden a una cuestionable visión del mundo y a un sistema de valores poco edificantes (Ortiz, 2007;GarcíaRuiz, Duarte \& Guerra, 2014).

\subsubsection{Sobre publicidad e información transmitida.}

Algo menos radicales parecen con que deba denunciarse el exceso de publicidad que pueda incitar a un consumo desmedido, por

\begin{tabular}{|l|c|c|c|c|}
\hline \multicolumn{1}{|c|}{ ÍTEMS } & MUY DE & $\begin{array}{c}\text { BASTANTE } \\
\text { DEE } \\
\text { ACUERDO }\end{array}$ & $\begin{array}{c}\text { DE } \\
\text { ACUERDO }\end{array}$ & $\begin{array}{c}\text { DESACUERDO O } \\
\text { POCO DE ACUERDO }\end{array}$ \\
\hline $\begin{array}{l}\text { Los programas que atenten contra } \\
\text { la intimidad y dignidad de las } \\
\text { personas deben prohibirse. }\end{array}$ & $89 \%$ & $11 \%$ & $0 \%$ & $0 \%$ \\
\hline $\begin{array}{l}\text { La exhibición de contenidos } \\
\text { violentos y sexuales } \text { en horario } \\
\text { protegido debe estar prohibida. }\end{array}$ & $88 \%$ & $12 \%$ & $0 \%$ & $0 \%$ \\
\hline $\begin{array}{l}\text { La presentación de modelos de } \\
\text { conducta poco deseables en las } \\
\text { series juveniles debe evitarse. }\end{array}$ & $82.5 \%$ & $14.3 \%$ & $3.2 \%$ & $0 \%$ \\
\hline $\begin{array}{l}\text { Los dibujos animados carentes de } \\
\text { valores cívicos deben eliminarse } \\
\text { de las programaciones infantiles. }\end{array}$ & $71.5 \%$ & $19 \%$ & $9.5 \%$ & $0 \%$ \\
\hline
\end{tabular}

Tabla 1. Grado de acuerdo de las responsables de las asociaciones de amas de casa de Asturias ante la necesidad de regular aspectos contemplados por la LGCA sobre la emisión de determinados contenidos. 
considerar que eso depende más de la receptividad del propio sujeto. Lo mismo sucede con su consideración respecto a que deban denunciarse las prácticas de manipulación o sesgo en la información que determinadas cadenas llevan a cabo, pues si bien están de acuerdo, los matices de muy de acuerdo (76\%), bastante de acuerdo (21\%) o simplemente de acuerdo (3\%) incluyen pequeñas variaciones respecto a las otras cuestiones (Tabla 2).

\subsection{Consideración sobre el cumplimiento} de la LGCA que hacen las televisiones para la protección de menores.

\subsubsection{Sobre aspectos formales.}

Se quiso conocer su opinión sobre la obligatoriedad de presentar -con razonable anticipación- la programación; incluir la calificación por edades en todos sus programas, así como indicar visual y acústicamente los considerados para mayores de 13 años (Art. 7, Pto. 6). La Tabla 3 refleja la visión crítica de las encuestadas para cada uno de los mencionados aspectos, donde cabe destacarse su conformidad (68\%) con que siempre las cadenas televisivas muestran su programación con anticipación, aunque un $17 \%$ denuncia prácticas de contraprogramación. Del mismo modo, un aproximado $66.5 \%$ señala que la mayoría de los programas que se emiten incluyen el indicativo de edades a las que se dirigen, pero un $17.3 \%$ manifiesta que hay cadenas que no lo hacen en todos sus programas e incluso en algunos está equivocado. De forma similar, el $66.5 \%$ afirma ver identificadas las señales visuales y acústicas en los programas dirigidos a mayores de 13 años, manteniéndose un $17 \%$ crítico que opina lo contrario.

Realizado el análisis estadístico mediante la prueba U de Mann-Whitney (véase Tabla 4), se pudo constatar que la detección de una falta de señalización por edades de los programas televisión de ciertas cadenas fue significativamente mayor para aquellas representantes de las asociaciones de amas de casa que manifestaron conocer la franja de protección horaria $(\mathrm{P}=0.015)$.

En este sentido, algunas asociaciones de consumidores denuncian que la información al consumidor es, en ocasiones, escasa y la

\begin{tabular}{|l|c|c|c|c|}
\hline \multicolumn{1}{|c|}{ ÍTEMS } & $\begin{array}{c}\text { MUY DE } \\
\text { ACUERDO }\end{array}$ & $\begin{array}{c}\text { BASTANTE } \\
\text { DE } \\
\text { ACUERDO }\end{array}$ & $\begin{array}{c}\text { DE } \\
\text { ACUERDO }\end{array}$ & $\begin{array}{c}\text { DESACUERDO O } \\
\text { POCO DE } \\
\text { ACUERDO }\end{array}$ \\
\hline $\begin{array}{l}\text { La publicidad engañosa debe retirarse } \\
\text { de las emisiones. }\end{array}$ & $88 \%$ & $12 \%$ & $0 \%$ & $0 \%$ \\
\hline $\begin{array}{l}\text { La incitación al consumismo feroz } \\
\text { debe denunciarse. }\end{array}$ & $81 \%$ & $9.5 \%$ & $9.5 \%$ & $0 \%$ \\
\hline $\begin{array}{l}\text { La transmisión de información } \\
\text { sesgada o manipulada es una práctica } \\
\text { denunciable. }\end{array}$ & $76 \%$ & $21 \%$ & $3 \%$ & $0 \%$ \\
\hline
\end{tabular}

Tabla 2. Grado de acuerdo de las responsables de las asociaciones de amas de casa de Asturias ante la necesidad de regular aspectos implícitamente contemplados por la LGCA sobre publicidad e información transmitida. 


\begin{tabular}{|l|c|c|c|c|}
\hline \multicolumn{1}{|c|}{ ÍTEMS } & SIEMPRE & A MENUDO & POCAS VECES & NUNCA \\
\hline $\begin{array}{l}\text { Muestran su programación } \\
\text { con antelación. }\end{array}$ & $68 \%$ & $15 \%$ & $14 \%$ & $3 \%$ \\
\hline $\begin{array}{l}\text { Incluyen la calificación por } \\
\text { edades en sus programas. }\end{array}$ & $66.5 \%$ & $16.2 \%$ & $12.5 \%$ & $4.8 \%$ \\
\hline $\begin{array}{l}\text { Señalan visual y } \\
\text { acústicamente los programas } \\
\text { para mayores de 13 años } \\
\text { durante toda su emisión. }\end{array}$ & $66.5 \%$ & $16.5 \%$ & $14 \%$ & $3 \%$ \\
\hline
\end{tabular}

Tabla 3. Opinión de las responsables de las asociaciones de amas de casa de Asturias sobre el cumplimiento que hacen las televisiones de aspectos formales regulados por la LGCA.

\begin{tabular}{|l|l|}
\hline U de Mann-Whitney & 805.000 \\
W de Wilcoxon & 1708.000 \\
Z & -2.435 \\
Sig.asintót.(bilateral) & 0.015 \\
\hline
\end{tabular}

Tabla 4. Diferencias significativas entre el grado de conocimiento de la franja de protección horaria y la falta de señalización por edades de los programas televisivos.

calificación por edades induce a error. Además, manifiestan que la asignación de calificaciones, en general, son incorrectas, pues programas que son para adultos no sólo se emiten en la franja infantil sino que además las edades para las que se recomiendan son claramente inapropiadas. Por todo lo cual, exigen al organismo competente que modifique las calificaciones, tengan mayor rigor y confieran esas competencias a especialistas para ofrecer una información adecuada al usuario (TAC, 2013).

\subsubsection{Sobre la emisión de determinados contenidos.}

El respeto a la intimidad y al anonimato de los menores aparece de forma explícita regulado por la LGCA, prohibiendo taxativamente la difusión de nombres, imágenes o datos de cualquier tipo que permitan identificarlos en hechos delictivos, así como hacerles protagonistas de las emisiones que puedan discutir su tutela o filiación. Del mismo modo, se prohíbe la emisión -tanto en abierto como en codificado- de contenidos que atenten contra la dignidad de las personas y los derechos humanos, así como, la emisión en abierto de contenidos pornográficos o de violencia gratuita.

Sobre la exhibición de contenidos que puedan atentar contra los derechos humanos, detectan, en raras ocasiones, ridiculización de minorías y desprecio a determinados colectivos. Un $85 \%$ de las mismas considera que las cadenas son respetuosas, tan sólo identificaron algunos programas que recreaban reportajes sobre abusos de menores, prostitución, malos tratos, etc. primando más el es- 
pectáculo que la denuncia, regodeándose en escenas escabrosas con alto contenido morboso (Tabla 5).

En relación a la emisión de contenidos violentos o de sexo explícito, el $15 \%$ declara que existen programas de determinadas cadenas que no sólo no cumplen el horario de protección de menores sino que claramente lo transgreden. Entre las cadenas que más incumplen las normativas, o se hallan en la frontera de lo punible, mencionan el programa «Dos hombres y medio» de Neox (grupo Antena 3); «La que se avecina» de Tele5; «Shing-Chan» de Neox (Grupo Antena 3); «Las Bandidas» de La1; la de animación «Padre de familia» (en inglés, Family Guy), etc. Coinciden con lo que recoge el informe de julio de 2013 de la Asociación de Consumidores de Medios Audiovisuales de Catalunya (TAC), donde se hace un análisis descriptivo muy exhaustivo de las vulneraciones, elegidas aleatoriamente, cometidas por las principales cadenas de televisión durante el año 2013.

Con relación a su actitud para mantener el anonimato de los menores implicados en hechos delictivos, mostrarles en shows o magazines, etc., el 5\% de las encuestadas manifiesta que las cadenas de televisión pocas veces cumplen lo regulado, señalando a Tele 5 como la que más lo incumple. Un 9.5\% indica que sólo a menudo lo cumplen, sobre todo cuando en algunas tertulias televisivas se discute la tutela de hijos de «famosos».

\subsubsection{Aspectos vinculados con el consu- mo, la publicidad y la salud.}

a) Emplazamiento de productos en la programación infantil. Los canales de televisión privada son los que de facto reinciden en este tipo de incumplimientos, pues son numerosos los espacios publicitarios que se insertan en las programaciones infantiles de Disney Chanel, Boing..., concretamente de cereales, golosinas, juegos, videojuegos, etc., los cuales forman parte inseparable de la programación infantil, mientras que en las cadenas públicas como el Clan de TVE no es así. Así lo percibe la totalidad de las encuestadas que, a pesar de ser una infracción directa de la LGCA y entender que se trata de una invitación directa a los niños al consumo, no consideran que ello suponga un riesgo desmedido directo para los menores, por entender que

\begin{tabular}{|l|c|c|c|c|}
\hline \multicolumn{1}{|c|}{ ÍTEMS } & SIEMPRE & $\begin{array}{c}\text { CASI } \\
\text { SIEMPRE }\end{array}$ & $\begin{array}{c}\text { A } \\
\text { MENUDO }\end{array}$ & $\begin{array}{c}\text { POCAS VECES O } \\
\text { NUNCA }\end{array}$ \\
\hline $\begin{array}{l}\text { Procuran no difundir nombre, imagen } \\
\text { etc. que puedan identificar a menores } \\
\text { en hechos delictivos o en emisiones que } \\
\text { discutan su tutela o filiación. }\end{array}$ & $63.5 \%$ & $22 \%$ & $9.5 \%$ & $5 \%$ \\
\hline $\begin{array}{l}\text { Procuran no emitir, ni en abierto ni en } \\
\text { codificado, contenidos que atenten } \\
\text { contra la dignidad de la persona. }\end{array}$ & $79 \%$ & $6 \%$ & $0 \%$ & $15 \%$ \\
\hline $\begin{array}{l}\text { Procuran no emitir en abierto } \\
\text { contenidos pornográficos o con } \\
\text { violencia gratuita. }\end{array}$ & $74 \%$ & $11 \%$ & $0 \%$ & $15 \%$ \\
\hline
\end{tabular}

Tabla 5. Opinión de las responsables de las asociaciones de amas de casa de Asturias sobre el cumplimiento que hacen las televisiones de lo regulado por la LGCA en materia de protección de menores.

Píxel-Bit. Revista de Medios y Educación. No 46. Enero 2015. ISSN: 1133-8482. e-ISSN: 2171-7966. doi: http://dx.doi.org/10.12795/pixelbit.2015.i46.11 


\begin{tabular}{|l|c|c|c|c|}
\hline \multicolumn{1}{|c|}{ ÍTEMS } & SIEMPRE & $\begin{array}{c}\text { CASI } \\
\text { SIEMPRE }\end{array}$ & $\begin{array}{c}\text { A } \\
\text { MENUDO }\end{array}$ & $\begin{array}{c}\text { POCAS VECES } \\
\text { O NUNCA }\end{array}$ \\
\hline $\begin{array}{l}\text { Respetan el horario de protección de } \\
\text { menores procurando no emitir, al menos } \\
\text { en esa franja, programas que promuevan } \\
\text { el culto al cuerpo directamente o puedan } \\
\text { generar rechazo a la autoimagen }\end{array}$ & $76 \%$ & $16 \%$ & $6.5 \%$ & $1.5 \%$ \\
\hline $\begin{array}{l}\text { Respeto de la emisión de publicidad de } \\
\text { bebidas alcohólicas de menos de } 20^{\circ} \\
\text { únicamente fuera del horario de } \\
\text { protección de menores }\end{array}$ & $74.5 \%$ & $19.2 \%$ & $1.5 \%$ & $4.8 \%$ \\
\hline $\begin{array}{l}\text { Respetan la prohibición de emitir } \\
\text { publicidad de bebidas alcohólicas de más } \\
\text { de } 20^{\circ} \text { en las cadenas televisivas }\end{array}$ & $78 \%$ & $11 \%$ & $5 \%$ & $6 \%$ \\
\hline
\end{tabular}

Tabla 6. Opinión de las responsables de las asociaciones de amas de casa de Asturias sobre el cumplimiento que hacen las televisiones de lo regulado por la LGCA en materia de publicidad y culto al cuerpo.

el supuesto gasto y consumo dependerá del nivel adquisitivo de las familias.

b) Publicidad y culto al cuerpo. Un tema bastante cuestionado es la promoción del culto al cuerpo que algunos programas televisivos y determinados spots publicitarios hacen de forma más o menos explícita, pudiendo provocar directa o indirectamente el rechazo a la propia autoimagen, y abocar a muchos niños y adolescentes a adoptar conductas autodestructivas y a sufrir trastornos alimentarios como la anorexia y/o la bulimia. Al preguntarles por si consideran que las cadenas de televisión respetan el horario de protección de menores procurando no emitir, al menos en esa franja, programas que promuevan el culto al cuerpo directamente o puedan generar rechazo a la autoimagen (véase Tabla 6), encontramos cierta conformidad pues el $76 \%$ de las encuestadas considera que siempre lo respetan, algún sector más crítico representado con un $16 \%$ matiza que casi siempre, otro $6,5 \%$ indica que lo hacen a menudo, y un $1.5 \%$ pocas veces o casi nunca.
Se constató que aquellas responsables de las asociaciones de amas de casa de Asturias que declararon percibir que las cadenas de televisión muestran con suficiente antelación la programación televisiva, manifestaron significativamente un mayor convencimiento de que éstas no emiten programas que promuevan el culto al cuerpo dentro del horario de protección de menores $(\mathrm{P}=0.007)$, tal y como quedo patente a través del análisis estadístico efectuado mediante la prueba de Kruskal-Wallis.

Si bien, se puede comprobar la sensibilidad que algunas cadenas de televisión muestran a este respecto, promoviendo campañas para una alimentación saludable subrayando la necesidad del consumo de fruta y verduras, etc. También hay otras que se caracterizan por programaciones en donde sus principales protagonistas, -socapa de cualquier tipo de concursos-, lucen cuerpos diez lindando con la estética anoréxica, proponiéndose como modelos de éxito, etc. Mientras, se presenta simultánea y contradictoriamente, otro tipo de publicidad que fomenta hábitos de alimentación que puede incrementar la obe- 
sidad infantil, tal como denuncia Perales (2011).

b.1) Publicidad de bebidas alcohólicas de menos de $20^{\circ}$.

Al preguntar si consideraban que las cadenas de televisión eran respetuosas, emitiendo publicidad de bebidas alcohólicas de inferior graduación (cervezas, vinos, sidras...) únicamente fuera del horario de protección de menores (véase Tabla 6), el 74.5\% respondió que observaban que lo hacían siempre, un $19.2 \%$ casi siempre, a menudo un $1.5 \%$, y pocas veces un $4.8 \%$, pues en ocasiones observan que los límites de las franjas horarias de protección vespertina lo vulneran, sobre todo si coincide con retransmisiones deportivas, que convocan a audiencias generalistas.

b.2) Publicidad de bebidas alcohólicas de más de $20^{\circ}$.

Un 78\% afirma que las televisiones cumplen la normativa siempre, y no emiten publicidad de bebidas alcohólicas de más de $20^{\circ}$ (véase Tabla 6); un $11 \%$ dice que casi siempre; a menudo lo señalan el 5\%; y un 6\% señala que pocas veces lo cumplen.

b.3) Publicidad de tabaco.

La crudeza de la legislación relativa a la prohibición de publicidad del tabaco (art. 18 de la LGCA) -junto a la de fumar en espacio públicos (Ley 42/2010 ${ }^{1}$ - ha contribuido a demonizar las campañas directas y promoción de este producto por sus implicaciones directas en la salud, además del miedo de las propias industrias del ramo a hacerlo explícitamente por las demandas millonarias que consumidores enfermos de cáncer han protagonizado, sentando precedente. Por ello, las distintas cadenas de televisión son bastante escrupulosas al respecto, hecho que justifica la consideración unánime de las encuestadas respecto al cumplimiento que se hace en esa materia.
Así pues, parece que las encuestadas consideran que la publicidad relativa a las bebidas alcohólicas y tabaco está bastante regulada y controlada, y que casi de forma unánime se cumple, o al menos así lo perciben ellas. Sin embargo, no sucede igual respecto a la publicidad que fomenta el culto al cuerpo y el aluvión publicitario que inunda los espacios infantiles de las cadenas televisivas privadas.

B) Opiniones recogidas de sus intervenciones en los grupos de discusión tras participar en el taller orientado a darles a conocer y analizar en profundidad la LGCA:

Concretamente, el visionado compartido de la programación televisiva con sus nietos les lleva a denunciar que «existen series de dibujos animados con contenidos adultos que se emiten en horario infantil (canal Boing)». También señalan que «los personajes de algunas series infantiles y juveniles (Disney Chanel) reproducen conductas poco ejemplares: refieren insultos, descalificaciones, difaman, injurian y amenazan a otros, hacen mal uso de los móviles y redes sociales para agredir a compañeros».

Del mismo modo, manifiestan que «algunas TV utilizan traillers con contenidos violentos y escenas de sexo explícito para avanzan la programación nocturna dentro del horario protegido (A3, Telecinco, La Sexta, Cuatro TV)». Además, se quejan de que «los fines de semana se emiten películas en la sobremesa que abordan temáticas adultas (violaciones, embarazos no deseados, violencia machista, secuestros, asesinatos, etc.) y echan de menos cine familiar que agrupe a todas las edades», «a veces no se advierte con antelación a qué público van dirigidas y hay que cambiar de canal al percatarse de los contenidos tratados». «Las familias confían 
en que hay un sistema para clasificar los programas, pero descubren que no siempre es así, ni siquiera en las cadenas públicas, o está confundido o induce a error, no es fiable».

También critican el vocabulario relajado, los tacos y la vulgaridad de algunos programas (Telecinco), los gritos y el trato vejatorio de participantes en tertulias (Sálvame de Luxe). Consideran muy grave que algunos famosos utilicen y exhiban a sus hijos involucrándoles en espectáculos mediáticos, invadiendo su intimidad pues puede afectarles en su vida cotidiana.

Respecto a la publicidad integrada en espacios o canales infantiles, no consideran que sea un riesgo para los menores, y se muestran más condescendientes. Por su parte, reconocen que en las emisiones deportivas de los canales generalistas se publicitan marcas de cerveza, aunque ello no les inquieta dado que suponen que la decisión de compra de esos productos compete a los adultos.

Por el contrario, denuncian la existencia de canales de esoterismo y brujería en abierto a los que pueden acceder fácilmente los menores, induciéndoles a hacer llamadas con altos costes y promover la superchería. Se escandalizan de que existiendo una Ley que regula todo eso no se tomen las medidas necesarias para hacerla cumplir, siendo más estrictos con las sanciones.

Los aspectos formales tales como avisar con antelación de los cambios de programación o la contraprogramación de las televisiones no suscita, en ellas, tanta preocupación como lo relativo a velar por la salud física y mental de los menores, no en vano se trata de sus nietos y nietas.

Concluidos los talleres formativos, orientados a fomentar la conciencia crítica de las telespectadoras y a promover su participación activa, se les solicitó que enumerasen sus propuestas, las cuales se recogen en un manifiesto que subraya su apuesta decidida por reclamar programas televisivos con contenidos positivos en el horario protegido que fomenten comportamientos pro-sociales, por ejemplo, que las series de ficción o dibujos animados presenten protagonistas que ayuden a quienes lo necesiten de forma altruista (realización de tareas profesionales, deberes escolares, etc.). Que se muestren historias que recreen la búsqueda y el encuentro de personas con diferentes puntos de vista, planteamientos ideológicos, creencias, etc. Se fomente la participación de todos los miembros de la familia en las tareas domésticas, eliminando planteamientos sexistas que encasillen a las mujeres. En definitiva, que encarnen valores como la solidaridad, reconocimiento y respeto por las minorías étnicas y colectivos desfavorecidos, etc. Entre otros, demandan la incorporación de programas o espacios televisivos divulgativos para el conocimiento de distintos ecosistemas, animales en extinción..., en los que se primen el respeto y protección de los animales y medio ambiente, donde los protagonistas sean niños o jóvenes que desarrollen actividades orientadas al cuidado de la naturaleza, prácticas de conservación de entornos naturales, prevención de incendios, reciclado de basuras, ahorro energético y de agua, fórmulas para evitar la degradación del paisaje, etc. Proponen la emisión de microespacios y/o documentales que contribuyan a sensibilizar a la audiencia frente a los problemas de colectivos desfavorecidos, abordando temáticas centradas en las necesidades de las personas dependientes, desempleados, inmigrantes, niños y niñas, ancianos, etc. Con objeto no sólo de dar a conocer las situaciones de marginalidad que sufren algunas personas, sino para concienciarles de la necesidad de 
buscar soluciones factibles para apoyarlas, denunciar las injusticias y evitar la discriminación, no regodearse en la miseria como espectáculo. Sugieren temáticas que recreen encuentros intergeneracionales: «¿qué puede enseñar tu abuelo/a a otros niños/as?», programas en donde los niños sean los hilos conductores que introduzcan a los mayores, dando lugar a escenarios de intercambio de las experiencias vitales de unos y de otros. Por ejemplo, mostrando oficios y profesiones tradicionales, la historia de un lugar, etc. Por último, proponen crear espacios de divulgación orientados a estimular en los telespectadores su conciencia crítica para en primer lugar, identificar y ser conscientes de las vulneraciones que en materia de protección a la infancia puedan efectuarse desde las cadenas televisivas, y en segundo lugar, saber formular las denuncias o quejas a la autoridad audiovisual pertinente o a cualquiera de las asociaciones locales existentes como la Asociación de Telespectadores y Radioyentes de Asturias (ATR-Asturias) o la de Consumidores y Usuarios de Asturias, u otras de ámbito nacional como las mencionadas OCU, ICMEDIA, TAC, etc.

\section{Discusión.}

Si bien es cierto que las televisiones, según manifiestan las telespectadoras consultadas, han incrementado su sensibilidad con la franja de protección de la infancia, sin embargo es necesario que se cumpla escrupulosamente lo contemplado en la LGCA (2010). Pues tal como denuncian Ruiz-San Román y González (2010), a pesar de que las televisiones públicas presentan programaciones más sensibles y respetuosas con el derecho de los menores a disfrutar de una televisión de calidad, sin embargo, las privadas se hallan en el límite, emiten algunos programas de contenidos cuestionables en horarios protegidos y, a menudo, en su afán por informar y captar audiencias, rompen las fronteras del derecho a la intimidad, buscando el sensacionalismo y la morbosidad de forma explícita. Por ello, se precisa de mayor firmeza para exigir que se cumpla lo especificado en la LGCA, para eliminar todo tipo de contenido que degrade a las personas y garantice una mejor protección de la infancia.

Las telespectadoras que formaron parte del estudio, abuelas en su mayoría, consideran necesario que las cadenas televisivas eviten la presentación de modelos de conducta poco deseable, así como la emisión de contenidos violentos o de sexo explícitos. Reclamación refrendada por la Asociación de Consumidores de Medios Audiovisuales de Cataluña (TAC, 2013), que evidencia que el $78 \%$ de los programas analizados vulneran el horario protegido, emiten programas con contenidos inapropiados para la infancia, que afectan a aspectos regulados explícitamente por la LGCA: vulneran la intimidad y el anonimato de los menores; atentan contra la dignidad de las personas y los derechos humanos; o exhiban pornografía o violencia gratuita. Contradictoriamente, llama la atención que el VII Informe de la Comisión Mixta de Seguimiento (octubre 2012), solo tenga registradas 67 quejas, de las cuales más de la mitad (40) son relativas a los incumplimientos de Sálvame (Tele5); 13 a El Diario (Antena 3), y el resto se reparten entre Neox (7), La Sexta (3), La Siete (2), La Sexta 3 (1) y Cuatro (1). Destacando las denuncias sobre el comportamiento social inadecuado de protagonistas o invitados a los programas y el tratamiento inadecuado de temáticas conflictivas, bajan las referentes a la presencia de contenidos de carácter violento o sexual, tal vez por el haber aumen- 
tado el umbral de tolerancia a ese respecto, como señalan las propias encuestadas al considerar que «los tiempos han cambiado mucho».

Otro aspecto que suscita su preocupación es la emisión en horario protegido de programas televisivos y spot publicitarios que inciden en el culto al cuerpo o presentan hábitos de alimentación de pueden incrementar la obesidad infantil. Sin embargo, son pocas las que denuncian estas transgresiones y las denuncias hechas al respecto por determinadas organizaciones no siempre prosperan debido a la vaguedad que enviste a la propia ley y a las lecturas subjetivas que protegen a las cadenas televisivas de pagos de multas, lo cual genera una sensación de impunidad que cuestiona el verdadero valor de la ley. Dichas quejas deberían dirigirse a la Comisión Mixta de Seguimiento, integrada al 50\% por cadenas y organizaciones sociales, que es el organismo encargado de recogerlas. Por su parte, el Comité de Autorregulación, integrado por representantes de las televisiones (excepto un representante de los periodistas), es quien decide su aceptación para elaborar la oportuna recomendación a la cadena infractora, siendo el Ministerio de Industria, Turismo y Comercio el que las sanciona. En 2012, tan solo 6 del total de reclamaciones fueron aceptadas por el Comité de Autorregulación, lo que constituye menos del $10 \%$ de las 67 presentadas por los espectadores. Datos que desmoralizan a las usuarias, demasiada burocracia inoperante, tal vez se debería atender a propuestas como las de Quintas y González (2014) que pasan por conferir más peso a la opinión de las audiencias a través de las redes sociales, destacando que las cadenas, como servicios públicos, tienen ahí un foro muy útil para escuchar las demandas de los usuarios.
Al menos, gran parte de las encuestadas consideran que la mayoría de las televisiones respetan la no emisión de publicidad de bebidas alcohólicas y tabaco en horario protegido. Subrayan la importancia de que exista mayor presencia ciudadana para detectar las infracciones, defender los derechos de los menores, y demandan una televisión de calidad. Sin duda, ello requiere formar y concienciar a los telespectadores, en tanto consumidores de los medios, para que sean inconformistas frente a la mediocridad y reclamen el respeto a la ley, mostrándoles los cauces oportunos para hacer viables sus demandas e impulsar su participación para que gane peso su voz, pues como sostienen Fuente, Martínez y del Prado (2014) existe una gran diferencia entre la consideración de los británicos por reclamar un derecho que como ciudadano tienen y el concepto de telespectador vulnerable que debe ser protegido, implícito en la normativa española.

\section{Conclusiones.}

En síntesis, la presente investigación recoge las opiniones y demandas formuladas por las 64 responsables de las 35 agrupaciones locales de las Asociaciones de Amas de Casa del Principado de Asturias, abuelas en su mayoría, comprometidas y sensibilizadas con el cuidado sobrevenido de sus nietos y preocupadas por el tiempo de ocio que éstos dedican a ver la televisión y, por ende, por el cumplimiento de la normativa de protección de la infancia que hacen los canales de televisión:

a) Sobre los horarios de protección de menores, regulados por la LGCA y los Códigos de Autorregulación, solicitan a la administración competente mayor rigor para hacer cumplir a las cadenas de televisión la ley 
y los compromisos libremente asumidos en relación a la protección de los menores, preservándoles de contenidos que lesionen sus derechos o contribuyan a desestabilizar su desarrollo socio-emocional. Exigiendo que las normativas vigentes no sean un atrezzo meramente estético, y que cuenten con especialistas para que valoren y tipifiquen aquellos contenidos que puedan dañarles o afectarles negativamente, y conforme a ello los clasifiquen por edades, como ya se contempla en la Unión Europea. En definitiva, que velen por favorecer escenarios mediáticos enriquecedores para los futuros ciudadanos que conformarán la sociedad del mañana.

b) Por otro lado, apelan a la responsabilidad de las cadenas de televisión para que respeten escrupulosamente las franjas horarias establecidas como espacios libres de contenidos perjudiciales para la audiencia infantil. Que no les sumerjan prematuramente en lo más execrable de la sociedad (violencia y abusos de todo tipo), o les utilicen como consumidores cautivos aprovechando los programas infantiles. Que informen con suficiente antelación a la audiencia no sólo de la programación que van a emitir, sino del tipo de contenidos que en ellas se priman, clasificándolas por edades como se explicita en la ley vigente.

c) Sobre los contenidos que se emiten, piden que no se priorice un canon de belleza que pueda atentar contra la salud o sobrevalore el culto al cuerpo, haciendo apología de la anorexia o bulimia. Ni que se apueste por hábitos de alimentación o consumo que entrañen riesgo para la salud de los menores $\mathrm{o}$ adolescentes en pleno desarrollo físico y psíquico. En esa misma línea, sugieren programas en los que se resalte los valores propios de la actividad física, deportividad, juego limpio... evitando destacar comportamien- tos que respondan a una competitividad exacerbada, sobre todo en algunas modalidades deportivas que exhiben escenarios de violencia lamentable.

d) Finalmente, el compendio de desideratas nada desdeñable que han formulado, va más allá de la mera protesta y desencuentro entre consumidores de los medios y responsables de los mismos, entraña una demanda de mayor calado, tal como la labor conjunta de programadores y especialistas en psicología infantil, pedagogos y educadores, que desde la convergencia busquen el entretenimiento y la formación de los menores desde los espacios televisivos. Propugnan fórmulas que defienden la responsabilidad compartida entre lo que deben difundir los medios, y lo que en el ámbito doméstico se debe permitir ver a los menores, si verdaderamente se les quiere proteger y evitar exponerles a contenidos perjudiciales como sostiene Bultó (2010). La intervención de las familias para que se cumplan las normativas y facilite a los menores espacios televisivos libres de contenidos violentos, pornográficos o de consumo desmedido que pongan en riesgo su estabilidad emocional y desarrollo psicológico, debería ser una prioridad. En ese sentido, sus propuestas pasan por diseñar programas con marcado carácter lúdico y educativo, donde se combine el entretenimiento con la cultura, como concursos integrados por juegos en los que puedan participar niños y niñas, que se aborden temas de forma atractiva y desenfadada, que complementen los contenidos curriculares que la audiencia infantil estudia en el ámbito escolar, que les sirvan de refuerzo, les acerquen a la ciencia y las artes, a conocer la historia de los pueblos, sus características idiosincrásicas, lengua, riqueza cultural, tradiciones, folclore, geografía. Favorezcan el 
desarrollo de competencias comunicativas, a partir del conocimiento de otras lenguas, por ejemplo, con la emisión de dibujos animados en versiones originales subtituladas, etc. $\mathrm{Al}$ estilo de las interesantes experiencias de programación televisiva existentes orientadas a la audiencia infantil en Gran Bretaña (BBC), Canadá (YTV), Japón (NHK), Brasil (TV), etc., que no pierden de vista la importancia de cuidar a los futuros ciudadanos, inculcando valores positivos, que se alejen de la recreación de lo más espurio de nuestra sociedad.

\section{Notas.}

${ }^{1}$ Ley 42/2010, de 30 de diciembre, por la que se modifica la Ley $28 / 2005$, de 26 de diciembre, de medidas sanitarias frente al tabaquismo y reguladora de la venta, el consumo y la publicidad de los productos del tabaco.

\section{Referencias bibliográficas.}

Bolivar, I.J. \& Flórez, A. (2004). La investigación sobre la violencia: categorías, preguntas y tipo de conocimiento. Revista de Estudios Sociales, 17, 32-41.

Boza, J. (2005). Las asociaciones de telespectadores en la construcción de una televisión de calidad. Comunicar, 25, 109-115.

Boza, L. (2005). Proyecto educativo, herramientas de educación audiovisual. Comunicar, 25, 177-180.

Buckingham, D. (2003). Media Education: Literacy, Learning and contemporary culture. UK: PolityPress.

Bultó, R. (2010). La protección del menor ante la televisión: una responsabilidad compartida. El ejemplo de CoAN en Navarra. En Blanco y Römer (coord.). Los niños frente a las pantallas. (pp. 325-333). Madrid: Editorial Universitas.
Del Moral, M.E. \& Villalustre, L.(2013). Alfabetización mediática, participación y responsabilidad frente a los medios de la generación del silencio. Comunicar, 40, 173-181. doi: 10.3916/C40-2013-03-08

Del Río, P.\& Del Río, M. (2008). La construcción de la realidad por la infancia española a través de su dieta televisiva. Comunicar, 31, 99-108. doi:10.3916/c31-2008-01-012

Fuente, C. (2010). El papel del asociacionismo audiovisual tras la LGCA. Las asociaciones de usuarios de los medios como agentes de la alfabetización mediática. Revista ICONO14, 8 (2), 102-117. doi: http:// dx.doi.org/10.7195/ri14.v8i2.270

Fuente, C., Martínez, J.M. \& del Prado, R. (2014). Las audiencias activas en la regulación de los medios: la dialéctica consumidorciudadano en España y México. Comunicar, 43, 91-99. doi: 10.3916/C43-2014-09.

Gabelas, J. A. \& Lazo, C. M. (2008). Consumo y mediaciones de familias y pantallas. Zaragoza: Gobierno de Aragón.

García-Ruiz, R., Duarte, A. \& Guerra, S. (2014). Propuesta de un instrumento de evaluación para medir el grado de competencia mediática en la etapa de educación infantil. Píxel-Bit. Revista de Medios y Educación, 44, 81-96. doi:10.12795/pixelbit.2014.i44.06

Guerra, S. \& René, P. (2010). La formación en medios y pantallas de las familias. PixelBit. Revista de Medios y Educación, 36, 193202.

Icmedia (2014). Informe sobre la protección del menor tras la Ley General de la Comunicación Audiovisual. Perspectivas y Retos. Disponible en http://www.icmedianet.org/wp/ ndog/wp-content/uploads/2014/01/ Proteccion-Menor1.pdf

Iguarta, J.J. (2008). La infancia construida: efectos pro-sociales y antisociales de los contenidos televisivos. Doxa Comunicación. 
Revista Interdisciplinar de Estudios de Comunicación y Ciencias Sociales, 6, 179-206.

Imbert, G. (2002). Violencia y representación: nuevos modos de ver y de sentir. Cultura y Educación, 14 (1), 33-41. doi:10.1174/ 113564002317348093

Kirkorian, H., Pempek, T., Murphy, L., Schmidt, M.\& Anderson, D. (2009). The Impact of Background Television on ParentChild Interaction.Child Development, 80 (5), 1350-1359.doi: 10.1111/j.1467-8624.2009. 01337.x

«Ley 7/2010, de 31 de marzo, General de la Comunicación Audiovisual de España». Boletín Oficial Del Estado (1 de abril de 2010), págs. 30157-30209.

«Ley 42/2010, de 30 de diciembre, por la que se modifica la Ley 28/2005, de 26 de diciembre, de medidas sanitarias frente al tabaquismo y reguladora de la venta, el consumo y la publicidad de los productos del tabaco». Boletín Oficial Del Estado (31 de diciembre de 2010), págs. 109188-109194.

Medrano, C., Cortés, P. A., Aierbe, A. \& Orejudo, S. (2010). Los programas y características de los personajes preferidos en el visionado de la televisión: diferencias evolutivas y de sexo. Cultura y Educación, 22 (1), 3-20. doi:10.1174/113564010790935196

Mestre, J.M., Guillen, J. \& Caro, F. (2012). Abuelas cuidadoras en el siglo XXI: recurso de conciliación de la vida social y familiar. Portularia: Revista de Trabajo Social, 12, 231-238. doi: 10.5218/PRTS.2012.0025

Ministerio De Sanidad, Política Social E Igualdad (2010). Informe sobre la encuesta mayores 2010. Madrid: IMSERSO.

Ministerio De La Presidencia De España (2012). VII Informe de la Comisión Mixta de Seguimiento del Código de Autorregulación sobre Contenidos Televisivos e Infancia. Disponible en http://www.tvinfancia.es
Ortiz, M.A. (2007). Redoblada trascendencia. La infancia ante el nuevo entorno audiovisual. Telos, 73. Recuperado de http:/ /telos.fundaciontelefonica.com/telos/ articulocuaderno.asp@idarticulo=10\&rev=73.htm

Pavón, F. (2005). Aprender desde la escuela y la familia a ver televisión de calidad. $\mathrm{Co}$ municar, 25, 221-224.

Perales, A. (2011). Evaluación del cumplimiento del Código de Autorregulación de Contenidos Televisivos e Infancia (2009). Madrid: Ministerio de Sanidad y Política Social.

Pereira, S., Pinto, M. \& Pereira, L. (2012). Recursos para la alfabetización mediática: investigación y propuestas para niños. Comunicar, 39, 91-99. doi: 10.3916/C39-2012-02-09 Pérez-Ornia, J. R. \& Núñez, L. (2006). Lo que ven los niños en la televisión. Revista de Estudios de Comunicación, 20 (11), 133-177.

Pérez-Ortiz, L. (2007). Las abuelas como recursos de conciliación entre la vida familiar y laboral. Presente y futuro. Madrid: Instituto de la Mujer.

Pinazo, S. \& Montoro, J. (2004). La relación entre abuelos y nietos: factores que predicen la calidad de la relación intergeneracional. Revista Internacional de Sociología (RIS), 38, 147-168. doi:10.3989/ris.2004.i38.257

Quintas, N. \& González, A. (2014). Audiencias activas: participación de la audiencia social en la televisión. Comunicar, 43, 83-90. doi: 10.3916/C43-2014-08

Ruiz-San Román, J. A. \& González, M. (2010). La experiencia española de autorregulación de contenidos televisivos en horario infantil. En E. Del Moral (coord.). Televisión: desarrollo de la creatividad e infancia. (pp. 47-54). Barcelona: Octaedro.

TAC (2013). Estudio sobre el cumplimiento de la Ley General de la Comunicación Audiovisual. Disponible en http:// 
taconline.net/wp-content/uploads/2013/07/ ESTCOMPLETO.pdf

Taveras, E., Sandora, T., Shih, M., RossDegnan, D., Goldman, D. \& Gillmann, M. (2006). The Association of Television and Video Viewing with Fast Food Intake by Preschool-Age Children.Obesity, 14 (11), 2034-2041. doi: 10.1038/oby.2006.238

Unesco Nordicom (1999). Recommendations addressed to UNESCO on Media Education. Conference Educating for the Media and the Digital Age.Disponible en h t t p : / / w w w . nordicom.gu.s e/s v / clearinghouse/recommendations-addressedunesco-media-education

VVAA (2004). Código de Autorregulación de Contenidos Televisivos e Infancia. Disponible en http://www.tvinfancia.es/ default.htm

Fecha de recepción: 10-07-2014

Fecha de evaluación: 03-10-2014

Fecha de aceptación: 24-10-2014 